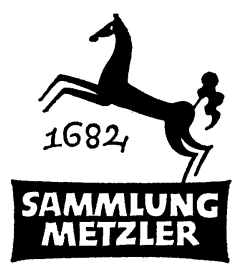

REALIENBÜCHER FÜR GERMANISTEN

ABT. D:

LITERATURGESCHICHTE 
HERBERT MEYER

\section{Eduard Mörike}

Zweite, verbesserte und ergänzte Auflage

MCMLXV

J.B. METZLERSCHE VERLAGSBUCHHANDLUNG

STUTTGART 


\section{r. Auflage r96r \\ 2. Auflage 1965}

ISBN 978-3-476-99118-8

ISBN 978-3-476-99117-1 (eBook)

DOI 10.1007/978-3-476-99117-1

\section{8}

(C) 1961 Springer-Verlag GmbH Deutschland

Ursprünglich erschienen bei J. B. Metzlersche Verlagsbuchhandlung und Carl Ernst Poeschel Verlag GmbH in Stuttgart 1961 


\section{INHALT}

\section{EINLEITUNG}

Gesamtausgaben, Dokumentationen, Biographien

LEBEN UND WERK

I. Kindheit und erste Jugendjabre I804-1822

2. Der Tübinger Stiftler $1822-1826$

3. Der Vikar I826-I834 19

4. Cleversulzbach $1834-1843$

5. Mergentheim I844-185I 36

6. Neubeginn in Stuttgart I85I-I860

7. Letzte Lebensjabre I86I-I875 48

Wirkungsgeschichte und Aufgaben DeR Forschung 53

Personenregister $\$ 59$

Register der erwähnten Werke Mörikes 60 


\section{AbKürzungen}

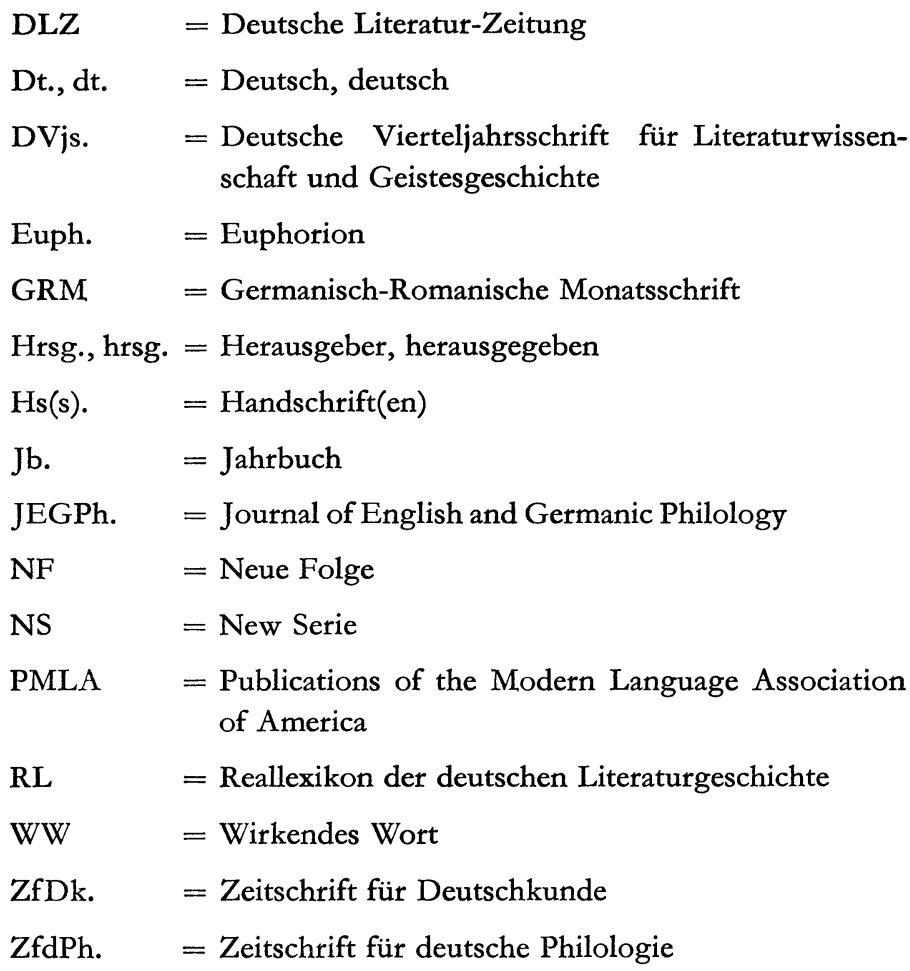


Chronologie der Buchausgaben von Mörikes Werken

I 832 Maler Nolten

I 838 Gedichte

I 839 Iris. Eine Sammlung erzählender und dramatischer Dichtungen (Der Schatz. Die Regenbrüder. Der letzte König von Orplid. Lucie Gelmeroth. Der Bauer und sein Sohn.)

I 840 Classische Blumenlese

r 844 Gedichte von Wilhelm Waiblinger

I 846 Idylle vom Bodensee

I 848 Gedichte. 2. Ausgabe

I 853 Das Stuttgarter Hutzelmännlein

I 855 Theokritos, Bion und Moschos (zusammen mit Notter)

Das Stuttgarter Hutzelmännlein. 2. Auflage

1856 Mozart auf der Reise nach Prag. 2 Auflagen

Idylle vom Bodensee. 2. Auflage

Gedichte. 3. Ausgabe

Vier Erzählungen (Der Schatz. Lucie Gelmeroth. Der

Bauer und sein Sohn. Die Hand der Jezerte).

I864 Anakreon und die sogenannten anakreontischen Lieder I 867 Gedichte. 4. Ausgabe

I873 Die Historie von der Schönen Lau (aus dem Hutzelmännlein). Mit 7 Umrissen von Moritz von Schwind. Gedichte. Titelauflage der Ausgabe von 1867. 